\title{
Respiratory Oscillations and Heat Evolution in Synchronously Dividing Cultures of the Fission Yeast Schizosaccharomyces pombe $972 \mathrm{~h}^{-}$
}

\author{
By R. K. POOLE AND D. LLOYD \\ Department of Microbiology, University College, Newport Road, Cardiff, CF 2 I TA \\ AND R. B. KEMP \\ Department of Zoology, University College of Wales, \\ Penglais, Aberystwyth, Cardiganshire
}

(Received 20 February 1973)

\begin{abstract}
SUMMARY
Large-scale synchronous cultures of the fission yeast Schizosaccharomyces pombe $972 \mathrm{~h}^{-}$were prepared by a sedimentation-velocity selection method in a zonal rotor. Oxygen uptake was measured polarographically on samples withdrawn at frequent intervals from the culture vessel. Rates of oxygen uptake, expressed per ml culture, increased exponentially, doubling over each cell cycle, but rose to maxima twice per cycle, once during cell division and once at approximately one-half of the cycle. Oxygen uptake at the maxima was stimulated by carbonyl-cyanide $m$-chlorophenyl hydrazone; that at the troughs was insensitive to this compound. Oxygen uptake was inhibited at all points in the cycle by antimycin A and cyanide at low concentrations; inhibition by these compounds did not alter the periodicity of the oscillations. Heat evolution increased at a constant rate during two cycles of synchronous growth, but in the presence of carbonyl-cyanide $m$-chlorophenyl hydrazone, peaks of heat evolution in phase with peaks of oxygen uptake were observed. The discontinuous respiratory activity of mitochondria through the cell cycle is discussed with reference to previous contrasting data, and possible control mechanisms are suggested.
\end{abstract}

\section{INTRODUCTION}

The use of cultures of micro-organisms, synchronized with respect to cell growth and division, has shown the cell cycle, that is the period between successive cell divisions, to be a series of discrete, temporally organized biochemical events. Measurements of oxygen consumption have been made on synchronized cultures of several micro-organisms, including yeast, with varying results. Rates of uptake, which increase in a series of abrupt steps but remain constant in the intervening periods, have been observed in Saccharomyces cerevisiae (Scopes \& Williamson, 1964; Greksák, Hariková \& Weissová, 197I), and in Schizosaccharomyces pombe (Osumi \& Sando, 1969; Marchant, 1971). These results are in contrast to patterns of oxygen uptake in $S$. cerevisiae observed by other workers, i.e. continuous rate increases observed by Cottrell \& Avers ( 1970 ), and the 'peak' patterns described by Nosoh \& Takamiya (1962) and Wiemken, von Meyenburg \& Matile (1970), in which oxygen uptake rises to a maximum and then declines again, once per cell cycle. Respiratory oscillations of this type, however, have not been further studied.

Interpretation of many of these results is complicated by imprecision in defining the cell cycle in yeasts which bear multiple buds, and the possibility of abnormal behaviour after nutritional and temperature shocks used to induce synchronized growth. 
In the present investigation, the advantages of using the fission yeast, Schizosaccharomyces pombe, in such studies (Mitchison, 1970) have been exploited by the use of synchronous cultures prepared by a large-scale cell-size selection method. Measurements of respiration and heat evolution, and the effects of an uncoupler of oxidative phosphorylation and of inhibitors of mitochondrial electron transport have been made. Such data may yield information on the regulation of mitochondrial activities, and mechanisms of biogenesis of mitochondria and their control. A preliminary account of part of this work has been presented previously (Poole \& Lloyd, 1972).

\section{Organism and growth conditions}

\section{METHODS}

Schizosaccharomyces pombe strain $972 \mathrm{~h}^{-}$was kindly supplied by Professor Urs Leupold (Institute of General Microbiology, University of Bern, Switzerland). Stock cultures were subcultured monthly and maintained at $4{ }^{\circ} \mathrm{C}$.

The defined growth medium $(\mathrm{pH} 5.5)$ containing $\mathrm{I} \%(\mathrm{w} / \mathrm{v})$ glucose was prepared as described by Mitchison (1970), but with $0.5 \%\left(\mathrm{NH}_{4}\right)_{2} \mathrm{SO}_{4}$ as nitrogen source. Solid medium contained $\mathrm{I} \cdot 5 \%$ (w/v) Ionagar no. 2 (Oxoid Ltd, London).

Starter cultures were grown in $200 \mathrm{ml}$ medium in I 1 conical flasks shaken for $20 \mathrm{~h}$ at $30{ }^{\circ} \mathrm{C}$ and $\mathrm{x} 50 \mathrm{rev} . / \mathrm{min}$ in a rotary orbital incubator (Gallenkamp \& Co., London, E.C. 2). Batch cultures (6-Iol) were grown in a laboratory Fermenter (L. H. Engineering Co., Ltd, Stoke Poges, Buckinghamshire). Forced aeration was at 11 air $/ 1$ culture $/ \mathrm{min}$, stirring at $400 \mathrm{rev} . / \mathrm{min}$. The growth temperature was $30^{\circ} \mathrm{C}$. Organisms were counted, following the criteria of Mitchison (1970), in a Thoma haemacytometer slide (Hawkesley, Lancing, Sussex) after suitable dilution. Cultures were inoculated to give an initial population of $\mathrm{I} \times 10^{6}$ organisms $/ \mathrm{ml}$ and harvested in the late exponential phase of growth, when the yeast population was between 2.2 and $2.6 \times 10^{7}$ organisms $/ \mathrm{ml}$. At this phase of growth, the organisms were glucose repressed (R. K. Poole, unpublished results).

\section{Preparation of synchronous cultures}

The method was based on the velocity-sedimentation selection method of Mitchison \& Vincent (I965), but utilized the greater gradient capacity offered by a zonal rotor. All sucrose solutions were made up in defined growth medium, and procedures performed at room temperature $\left(\mathrm{I} 8^{\circ} \pm 2{ }^{\circ} \mathrm{C}\right.$ ). Linear sucrose gradients ( 10 to $60 \%$, w/w; total vol. $540 \mathrm{ml}$ ) were generated and loaded into the M.S.E. HS zonal rotor in an M.S.E. I 8 centrifuge by means of an Isco 'Dialagrad' Pump (Shandon Southern Instruments Ltd, London). Loading was at $600 \mathrm{rev} / \mathrm{min}$; the remainder of the rotor volume was filled with $60 \%(\mathrm{w} / \mathrm{w})$ sucrose.

The culture (IO l) was rapidly concentrated to $300 \mathrm{ml}$ by using the continuous-flow rotor (with a 'high efficiency' insert) of the M.S.E. I 8 centrifuge at $4000 \mathrm{rev} . / \mathrm{min}$ ( $570 \mathrm{~g} ; r_{\mathrm{av}}$. $3 \mathrm{~cm}$ ) and a flow rate of approx. $500 \mathrm{ml} / \mathrm{min}$. The concentrated suspension was quantitatively sedimented in the $6 \times 250 \mathrm{ml}$ rotor of the same centrifuge by acceleration to $5000 \mathrm{rev} . / \mathrm{min}$, followed by immediate deceleration. The yeast pellet ( 20 to $30 \mathrm{~g}$ wet wt) was resuspended to $70 \mathrm{ml}$ in $5 \%(\mathrm{w} / \mathrm{w})$ sucrose and homogenized ( 3 strokes) in a loose-fitting hand homogenizer (Jencons Scientific Ltd, Hemel Hempstead, Hertfordshire).

The suspension was pumped onto the gradient at approx. $15 \mathrm{ml} / \mathrm{min}$ followed by an overlay of $30 \mathrm{ml}$ defined medium. The rotor was accelerated to $1450 \mathrm{rev} . / \mathrm{min}$ for 5 to $8 \mathrm{~min}$ until the band of yeast had sedimented about half the path length of the rotor. The rotor was unloaded at $600 \mathrm{rev} . / \mathrm{min}$ at $30 \mathrm{ml} / \mathrm{min}$ and fractions (IO ml) collected; 4 to 6 fractions con- 
taining small slowly-sedimenting organisms were used to inoculate 2 to 41 defined medium to give an initial population of 3 to $6 \times 10^{6}$ organisms $/ \mathrm{ml}$, maintained under the conditions described above, except that stirring was at $200 \mathrm{rev}$./min. Integrated field time of centrifugation, from the point of loading half the sample volume to collection of fractions used for inoculation, was within the range:

$$
\int_{0}^{t} \omega^{2} d t=920-\mathrm{I} 300 \mathrm{rad}^{2} \cdot \mathrm{s}^{-1}
$$

Assessment of synchrony'

Yeast numbers were measured periodically and the degree of synchrony assessed by the synchrony index of Blumenthal \& Zahler ( 1962 ), calculated from the equation:

$$
F=\left(N / N_{0}\right)-2^{t i g},
$$

where $F$ has a maximum value of $\mathrm{I} \cdot 0$ in a culture exhibiting theoretically perfect synchrony, $N=$ number of organisms at time $t, N_{0}=$ number of organisms at zero time, $g=$ mean generation time.

In the presentation of results, vertical lines indicate the mid points of doublings in yeast numbers, and $F_{1}$ and $F_{2}$ denote synchrony indices of the first and second doublings in yeast numbers, respectively.

\section{Analytical methods}

Measurement of oxygen uptake. Samples were removed at frequent intervals during the first $6 \mathrm{~h}$ of synchronous growth, and oxygen uptake measured polarographically (Lloyd \& Brookman, 1967). Antimycin A $(0.01 \mathrm{mg} / \mathrm{ml})$ and carbonyl-cyanide $m$-chlorophenyl hydrazone (CCCP) (I mg/ml) were used as methanolic solutions. Dicyclo-hexyl-carbo-diimide (DCCD) $(10 \mathrm{mg} / \mathrm{ml})$ was dissolved in $10 \%(\mathrm{v} / \mathrm{v})$ methanol (Kovač, Galeotti \& Hess, I968). Volumes of addition were such that the final methanol concentrations never exceeded $0.3 \%(\mathrm{v} / \mathrm{v})$, and appropriate controls were performed to allow for the effects of methanol on respiration rates. KCN was used in aqueous solution (O.O I M). Warburg manometry was performed with conventional apparatus (Umbreit, Burris \& Stauffer, 1957).

Measurements of heat evolution. These were made using a heat conduction flow microcalorimeter (LKB I0700-I) based on a design by Wadsö (I 968) and Monk \& Wadsö (I 968). In one experiment, the yeast suspension was pumped from the culture vessel at a constant flow rate of $80 \mathrm{ml} / \mathrm{h}$ to a T-piece, where it was mixed with a constant flow of air $(80 \mathrm{ml} / \mathrm{h})$ and thence into the stainless-steel flow cell (vol. I.4 ml; Erikson \& Wadsö, I971) of the instrument. In a second experiment, samples $(10 \mathrm{ml})$ were removed at time intervals and CCCP added to a final concentration of $0.16 \mu \mathrm{M}$. The mixture was maintained at $30{ }^{\circ} \mathrm{C}$ and pumped (after pulsing with air, $20 \mathrm{ml} / \mathrm{h}$ ) into the calorimeter (total flow rate $70 \mathrm{ml} / \mathrm{h}$ ) until a steady state of heat evolution within the flow cell was obtained ( 12 to $13 \mathrm{~min}$ ). Between samples the flow cell was flushed through with defined medium. In both experiments, the time for yeasts to enter the flow cell after leaving the culture vessel did not exceed $5 \mathrm{~min}$; preliminary experiments indicated that $\mathrm{O}_{2}$ did not become limiting for respiration during this period. Temperature of the thermostatic air bath was $30{ }^{\circ} \mathrm{C}$; water at $28{ }^{\circ} \mathrm{C}$ was used to assist dissipation of heat from the instrument. The amplification range was set at 30 or $100 \mu \mathrm{V}$. A baseline was established before and after the experiment by pumping medium at the appropriate rate through the instrument. This baseline showed no appreciable drift during the course of the experiment. Thermograms were recorded on a Phillips Potentiometric Recorder with a full scale deflexion of $100 \mathrm{mV}$. The instrument was calibrated at the 

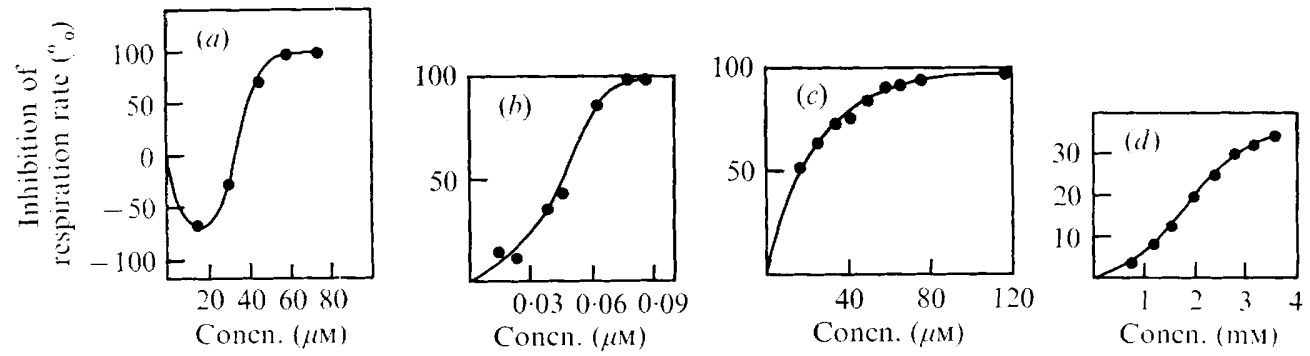

Fig. I. Effect of uncouplers and inhibitors on respiration of cells from exponentially growing cultures of Schizosaccharomyces pombe. Oxygen-uptake measurements were made on undiluted samples withdrawn from cultures during the exponential phase of growth. Numbers of organisms $/ \mathrm{ml}$ in individual experiments are in parentheses: (a) CCCP $\left(3.7 \times 10^{7}\right) ;(b)$ antimycin $\mathrm{A}\left(3.0 \times 10^{7}\right) ;(c) \mathrm{KCN}$ $\left(2 \cdot 3 \times 10^{7}\right) ;(d) \operatorname{DCCD}\left(2.5 \times 10^{7}\right)$.

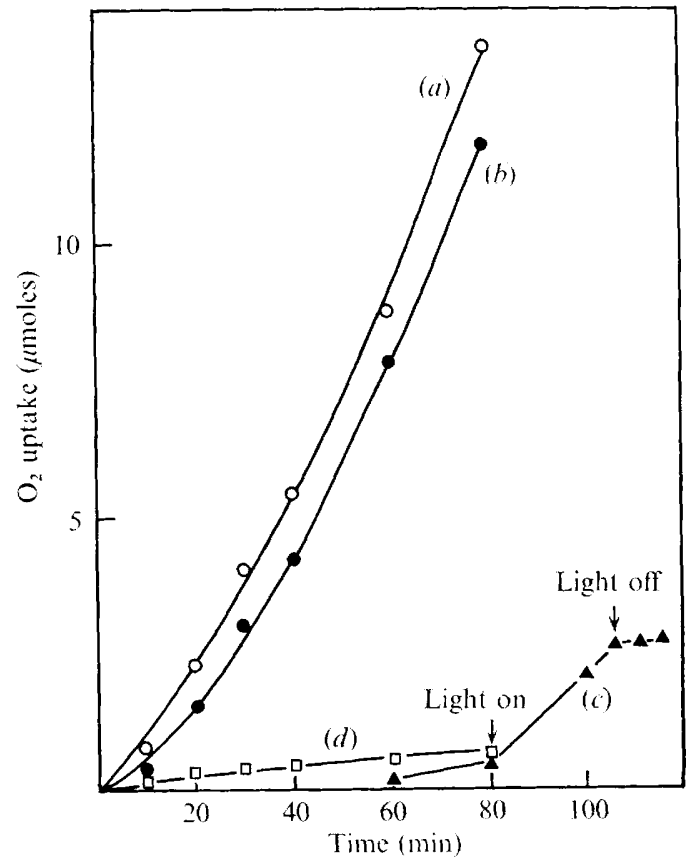

Fig. 2. Light-reversible inhibition by $\mathrm{CO}$ of respiration of non-proliferating suspensions of Schizosaccharomyces pombe. Each manometer flask contained $0.36 \mathrm{mmol} \mathrm{KOH}$ in the centre well, $20 \mathrm{~mm}$-potassium phosphate buffer, pH 5.4, and approx. $2 \times 10^{8}$ washed, log-phase cells in the main compartment, and unless indicated, glucose in the side arm to give a final concentration of $\mathrm{I} \%$ $(\mathrm{w} / \mathrm{v})$. Total liquid volume was $3.0 \mathrm{ml}$. Flasks were shaken at $120 \mathrm{cyc} / \mathrm{min}$ and $30^{\circ} \mathrm{C}$ in the dark. At the time shown, white light ( $300 \mathrm{~W}$ tungsten lamp at a distance of $15 \mathrm{~cm}$ ) illuminated the flasks. Gas phases used in individual flasks were: air $(a, d) ; \mathrm{N}_{2}: \mathrm{O}_{2}, 19: 1(b)$; and $\mathrm{CO}: \mathrm{O}_{2}, 19: 1$ (c). Control flask $(d)$ lacked substrate only.

end of the experiment, with aerated medium flowing through the cell, by applying an internal current of $\mathrm{I} \cdot 0$ or $\mathrm{I} \cdot 5 \mathrm{~mA}$ for 800 or $1000 \mathrm{~s}$ to achieve a steady state. The calibration was recorded in $\mu \mathrm{W}$.

Protein. Total cell protein was determined in $0.5 \mathrm{M}-\mathrm{NaOH}$ extracts as described by Herbert Phipps \& Strange (I97I) with dry bovine serum albumin as standard. 


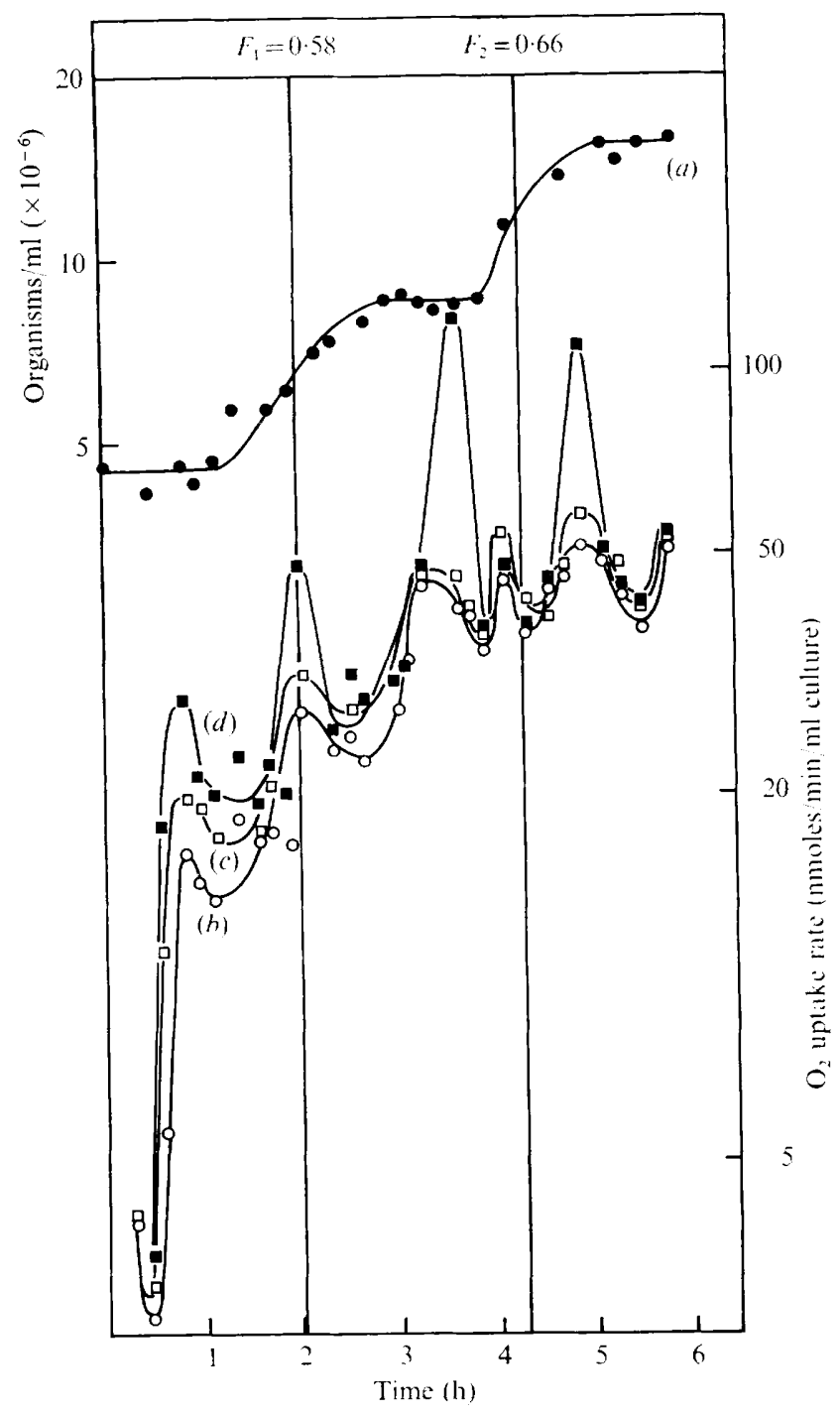

Fig. 3. Oxygen uptake of yeast suspensions from a synchronous culture of Schizosaccharomyces pombe and effect of CCCP. $F_{1}$ and $F_{2}$ denote synchrony indices of the first and second doublings in cell numbers $(a)$ respectively. Oxygen uptake measurements on culture samples removed at frequent intervals from a synchronous culture were made in the absence $(b)$ or the presence of $8 \cdot 1 \mu \mathrm{M}$ CCCP $(c)$ or $16.2 \mu \mathrm{M}-\mathrm{CCCP}(d)$.

Chemicals. Antimycin A was from Sigma (London) Chemical Co., London, S.W. 6, CCCP from Calbiochem, Los Angeles, California, U.S.A.; KCN and DCCD from B.D.H. Chemicals Ltd, Poole, Dorset; Bovine-serum albumin from Armour Pharmaceutical Co., Eastbourne, Sussex. The sucrose used was mineral-water sugar from Tate \& Lyle Ltd, Cardiff. 
(a)

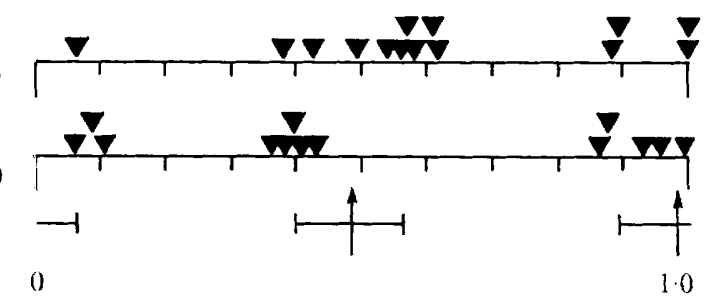

Scheme I. Cell cycle maps of timings of maxima of oxygen uptake in synchronous cultures of Schizosaccharomyces pombe. The abscissa represents the cell cycle, taken as the period between the mid-points of the first and second doublings in cell numbers, as a linear scale extending from $O$ to $\mathrm{I} \cdot \mathrm{O}$. Each triangle clenotes the maximum rate of oxygen uptake observed in the period before the first doubling in numbers $(a)$ or in the following complete cell cycle $(b)$. Arrows with cross bars are mean value with standard deviations.

\section{RESULTS}

Effects of uncouplers and inhibitors on respiration cells from exponentially growing cultures

At concentrations greater than $30 \mu \mathrm{M}, \mathrm{CCCP}$ acted as an inhibitor of respiration; inhibition was complete at $60 \mu \mathrm{M}$ Respiration rate was accelerated at concentrations less than $30 \mu \mathrm{M}$ and maximum stimulation effect was produced at $\mathrm{I} 6 \mu \mathrm{M}$ (Fig. I $a$ ).

Antimycin A $(0.045 \mu \mathrm{M})$ gave $50 \%$ inhibition of respiration; inhibition was virtually complete at $0.08 \mu \mathrm{M}$ (Fig. I $b$ ). The respiration rate of an exponentially growing culture was $50 \%$ inhibited on adding I $6 \mu \mathrm{M}-\mathrm{KCN} ; 0.12 \mathrm{mM}-\mathrm{KCN}$ gave $98 \%$ inhibition (Fig. I $c$ ). High concentrations $(4 \mathrm{mM})$ of DCCD produced $30 \%$ inhibition of respiration rate of similar cultures (Fig. I $d$ ).

Manometric measurements of oxygen uptake indicated that the respiration rate of nonproliferating yeast suspensions in the presence of $\mathrm{I} \%$ glucose was virtually unaffected by replacing air by a 19:I mixture $\mathrm{N}_{2}: \mathrm{O}_{2}$ as the gaseous phase (Fig. $2 a, b$ ), whereas 19:I $\mathrm{CO}: \mathrm{O}_{2}$ (Fig. $2 c$ ) gave almost complete inhibition. Inhibition by $\mathrm{CO}$ was reversible on illumination with white light. Endogenous respiration rate in the absence of added glucose (Fig. $2 d$ ) and with a gas phase of air was only $5 \%$ of the glucose-supported respiration.

\section{Oxygen uptake of suspensions from a synchronous culture and the effect of CCCP}

Yeast counts increased in a stepwise fashion through two doublings in numbers (Fig. $3 a$ ). The mean duration (with standard deviation) of the first full cell cycle, measured in 17 separate experiments, was $2 \cdot 65 \pm 0.19 \mathrm{~h}$. This compares with a mean generation time of $2 \cdot 70 \mathrm{~h}$ for an exponentially growing culture (Poole \& Lloyd, 1973). Synchrony indices for the first and second cell divisions, expressed as $F_{1}$ and $F_{2}$ in the Figures, varies between 0.6 and 0.9 , comparing favourably with those obtained by other workers (Mitchison, I97I). Respiration rates of undiluted samples from the culture vessel increased exponentially overall, and doubled between successive cell divisions but rose to maxima twice per cell cycle (Fig. $3 b$ ). The first maximum occurred during the phase of cell elongation before cell division (Mitchison, 1957); the second maximum coincided with the first doubling in cell numbers. This pattern was then repeated. Mean amplitude of the oscillations (i.e. peak to trough) with standard deviation was $32 \% \pm 10.6 \%$ ( 16 ) of the total respiration as measured at the maxima. Oscillations of smaller amplitude sometimes occurred at the minima described above. Scheme I shows a summary of results obtained in 14 separate cell cycles. There was good agreement in the separate experiments on the timing in the cell cycle at which the two maxima 


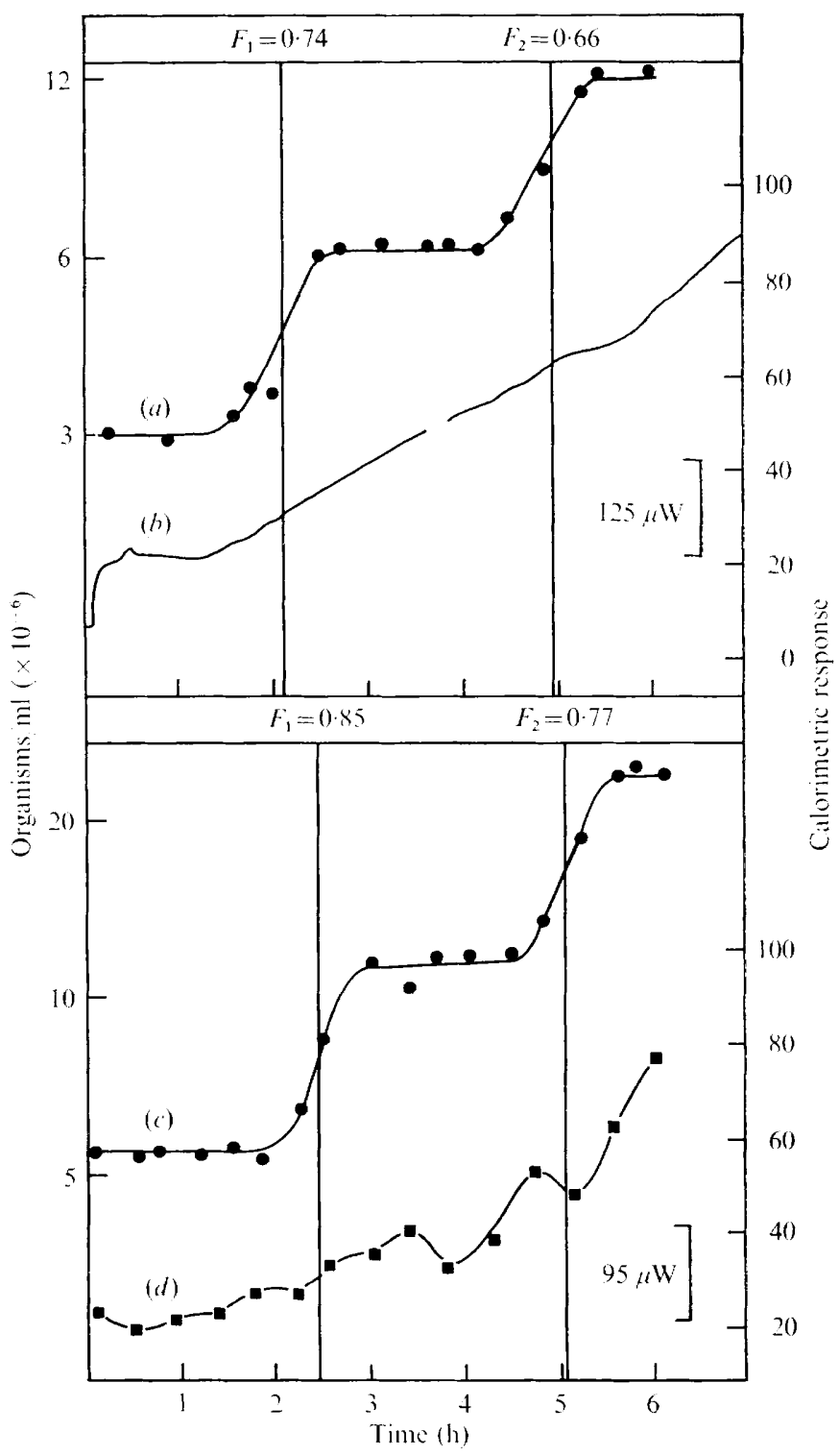

Fig. 4. Heat evolution of a synchronous culture of Schizosaccharomyces pombe and of samples incubated with CCCP. Heat evolution $(b)$ was measured continuously by using a flow microcalorimeter, through two doublings in yeast numbers $(a, c)$. In a separate experiment, samples removed from a synchronous culture and incubated with $16 \mu \mathrm{M}-\mathrm{CCCP}$, were pumped in turn into the instrument to achieve a steady state of heat evolution $(d)$. In both experiments, $F_{1}$ and $F_{2}$ denote synchrony indices of the first and second doublings in yeast numbers, respectively.

were observed. Mean values (with standard deviations) were $0.48 \pm 0.084$ (I 4 ) and $0.98 \pm$ 0.074 (13), where I.0 represents the length of the cell cycle.

Similar results were obtained when oxygen consumption was measured manometrically in a Gilson (Anachem Ltd, Luton, Bedfordshire) respirometer on synchronous cultures $(2 \mathrm{ml})$ growing in the manometric flasks. 


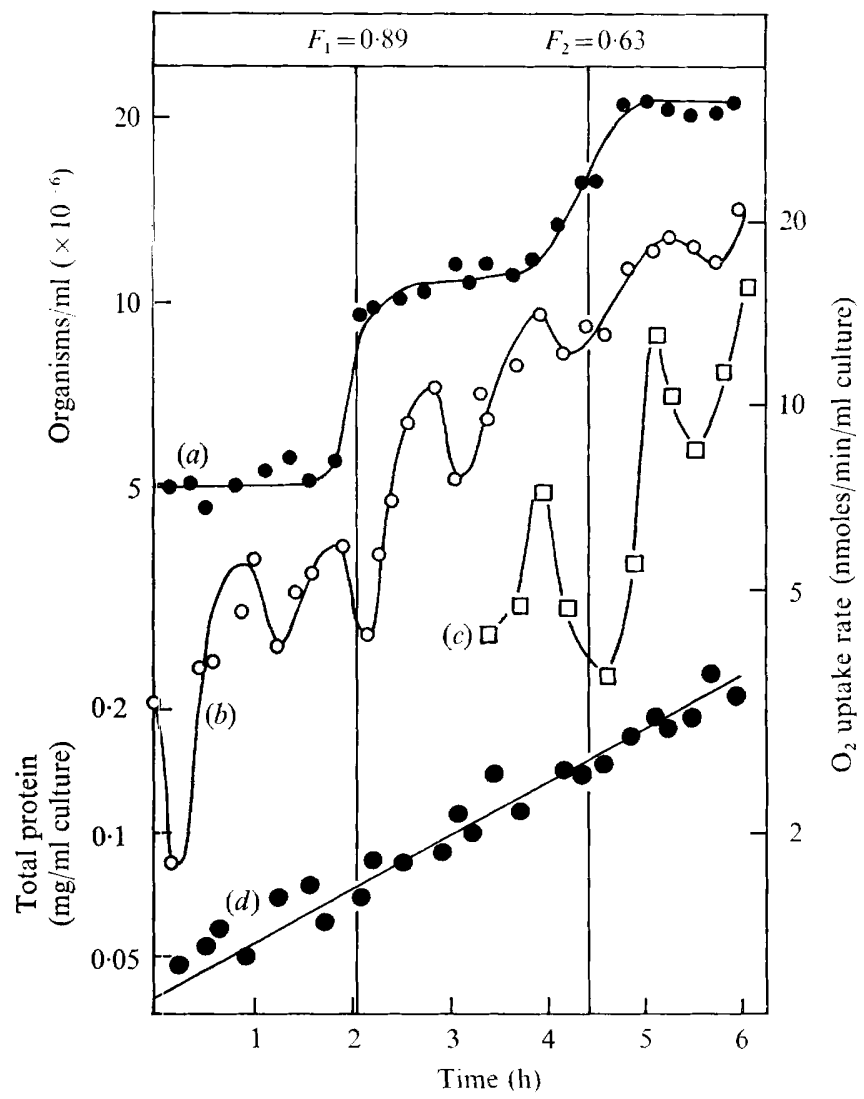

Fig. 5. Oxygen uptake of yeast suspensions from a synchronous culture of Schizosaccharomyces pombe and effect of antirnycin A. $F_{1}$ and $F_{2}$ denote synchrony indices of the first and second doublings in yeast numbers $(a)$ respectively. Oxygen-uptake measurements were on culture samples removed at frequent intervals from a synchronous culture in the absence $(b)$ or the presence $(c)$ of $0.023 \mu \mathrm{M}$-antimycin $\mathrm{A} ;(d)$ shows total cell protein $(\mathrm{mg} / \mathrm{ml})$ culture.

Addition of $8 \cdot 1 \mu \mathrm{M}-\mathrm{CCCP}$ (Fig. $3 \mathrm{c}$ ) produced between 9 and $27 \%$ acceleration of respiration at the maxima of oxygen uptake but only between 3 and I $8 \%$ acceleration of respiration at its minima. At this concentration, the stimulating effect of CCCP decreased throughout the experiment as yeast numbers increased. Doubling the uncoupler concentration (Fig. $3 d$ ) to a level previously found to be sufficient to give maximum stimulation at the highest cell concentration, gave between 70 and $170 \%$ acceleration of respiration rates at the maxima, but only between 6 and $18 \%$ at the minima.

\section{Heat evolution of a synchronous culture}

At the time of inoculation, aerated culture flowing into the microcalorimeter gave a calorimetric response greater than that produced by uninoculated medium by an amount which remained steady until shortly before the first doubling in cell numbers (Fig. $4 a$ ). Heat production then increased at a constant rate, doubling over one complete cell cycle (Fig. $4 b$ ).

Heat evolution in the presence of CCCP of samples from a synchronous culture

Culture samples incubated in the presence of $16 \mu \mathrm{M}-\mathrm{CCCP}$ gave an overall exponentially increasing but discontinuous calorimetric response through the cell cycle (Fig. $4 d$ ). After the 


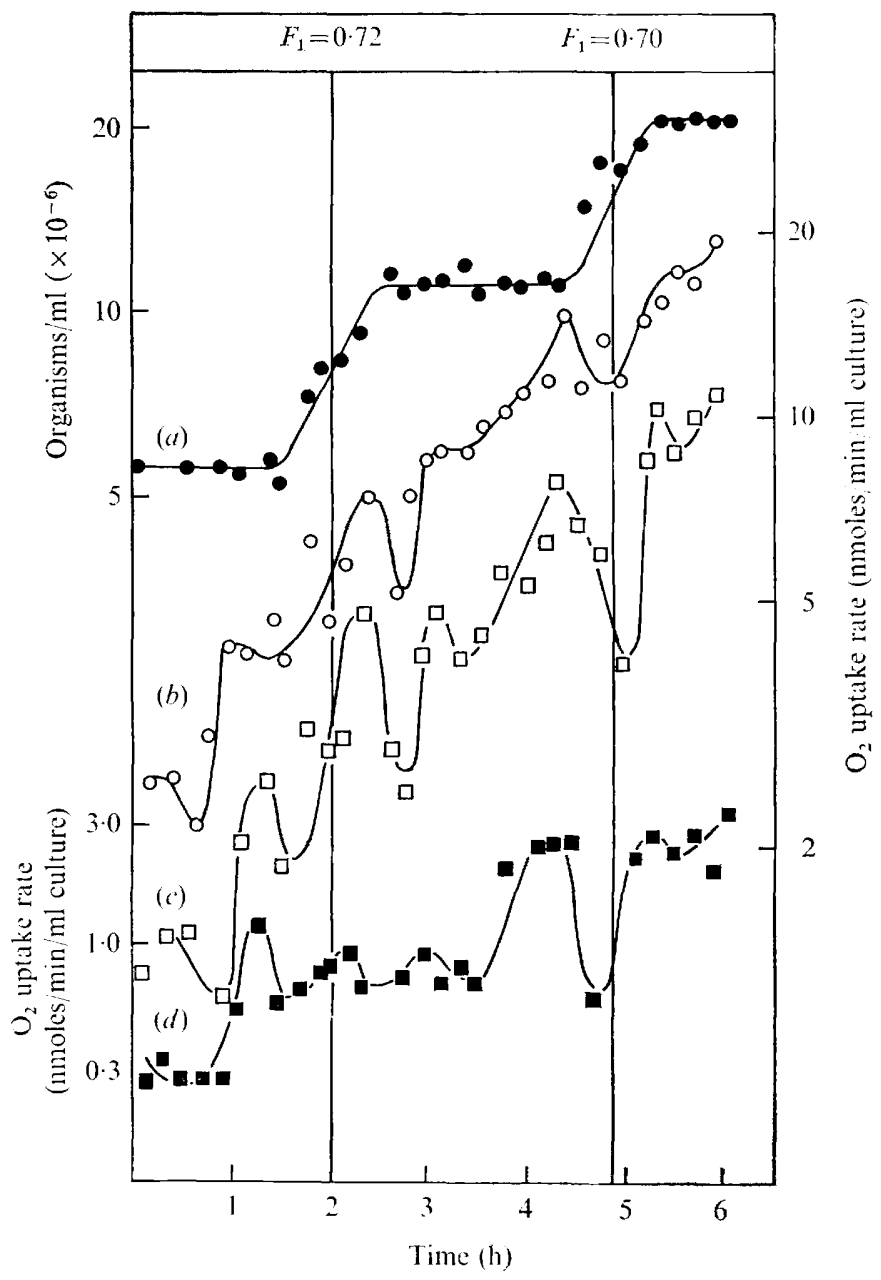

Fig. 6. Oxygen uptake of yeast suspensions from a synchronous culture of Schizosaccharomyces pombe and effect of $\mathrm{CN}^{-} . F_{1}$ and $F_{2}$ denote synchrony indices of the first and second doublings in yeast numbers $(a)$ respectively. Oxygen uptake measurements on culture samples removed at frequent intervals from a synchronous culture were made in the absence $(b)$ or the presence of $25 \mu \mathrm{M}$ $\mathrm{KCN}(c)$ or $0.1 \mathrm{~mm}-\mathrm{KCN}(d$; lower ordinate scale).

first doubling in cell numbers (Fig. 4c), a maximum of heat evolution corresponded in time with that previously observed for oxygen uptake. As also with oxygen uptake, the next maximum occurred slightly before the second doubling in cell numbers.

Oxygen uptake of yeast suspension from a synchronous culture, and the effects of antimycin $A$ and $\mathrm{CN}^{-}$

Addition of $0.023 \mu \mathrm{M}$-antimycin A to undiluted samples withdrawn from a synchronous culture indicated that the respiration rate proceeding in the presence of this inhibitor (Fig. $5 c$ ) oscillated with the same periodicity as that of uninhibited suspensions (Fig. $5 b$ ). Overall respiration rate was inhibited $54 \%$ by this concentration. Calculation of the peakto-trough amplitudes indicated that the oscillating component of respiration was relatively uninhibited. A decrease in the degree of inhibition obtained with a constant level of anti- 
mycin A accompanied the exponential increase in total cell protein shown in Fig. $5(d)$. Two such experiments showed essentially similar results. Addition of $25 \mu \mathrm{M}-\mathrm{KCN}$ (Fig. $6 c$ ) inhibited the mean respiration rate by $52 \%$ but the oscillating component of respiration was relatively uninhibited and showed no change in frequency. Higher concentrations of $\mathrm{CN}^{-}$ ( $100 \mu \mathrm{M}$, Fig. $6 d$ ) did, however, attenuate the oscillations in suspensions where the mean respiration was $92 \%$ inhibited. Again the periodicity of oscillations was unchanged. A total of three such experiments gave essentially similar results.

\section{DISCUSSION}

During the period between successive doublings of cell numbers of Schizosaccharomyces pombe, total cell protein and respiration increased exponentially, whilst heat evolution in the absence of CCCP increased at a linear rate. All these parameters doubled in magnitude during the cell cycle, which was similar in length to that of the mean generation time of exponentially growing cultures. Thus, synchronous cultures prepared by the large-scale method of size selection described, satisfied some of the criteria of 'balanced' growth (Campbell, I957).

The oscillatory pattern of respiration observed contrasts with the single stepwise increases observed during the cell cycle in cultures of Schizosaccharomyces pombe synchronized by a nutritional induction method in complex growth medium (Osumi \& Sando, I969); these authors claimed to have found a doubling of mitochondrial numbers per cell coinciding with the abrupt increases in respiration rate.

That no oscillation of heat production occurs in the growing culture suggests that the oscillatory component of respiration is involved in energy conservation. This is confirmed by the observation that the addition of the appropriate concentration of uncoupling agent produced up to $170 \%$ stimulation of respiration rate and $30 \%$ increase in heat production in yeasts at either of the two maxima which occur in a single cell cycle. Addition of CCCP at the minima had little stimulatory effect on respiration and, assuming that this compound could penetrate freely to all sites of energy conservation, two alternative explanations may be offered: (i) the coupling of oxidative phosphorylation does not limit the overall respiration rate at these minima; or (ii) electron transport is already almost completely uncoupled from the energy conservation reactions at these times in the cell cycle. If alternative (i) is correct, at all times in the cycle a considerable proportion of the total heat production in synchronously dividing cultures arises from respiration which is not involved in ATP formation. About $30 \%$ of the respiratory activity of exponentially growing cultures of Schizosaccharomyces pombe is inhibited by DCCD; a similar result for non-proliferating yeast suspensions has previously been reported by Kovač et al. (I968) and may indicate that energy conservation is only loosely coupled in both non-growing and exponentially growing cultures. The failure of an uncoupling agent to stimulate respiration at the minimal rates of oxygen uptake, clearly indicates that the control mechanism producing the oscillatory response is not respiratory control, i.e. the rate limitation of electron transport in phosphorylating respiratory chains produced by limited availability of ADP (Chance \& Williams, I956).

Complete inhibition of respiration of exponentially growing cultures can be produced by antimycin $\mathrm{A}$ or by $\mathrm{KCN}$ or $\mathrm{CO}$, classical inhibitors of the mitochondrial electron-transport chain at sites II and III respectively. This indicates the absence of any considerable alternative pathway of electrons to oxygen in Schizosaccharomyces pombe. Insensitivity to rotenone (Heslot, Goffeau \& Louis, I970) or piericidin A (R. K. Poole, unpublished), however, suggests that energy conservation may not occur at Site I. Sensitivity to inhibition by anti- 
mycin A or by $\mathrm{KCN}$ was greater at times in the cell cycle when respiration was minimal rather than when it proceeded at a maximum, and thus a concentration of either inhibitor giving about $50 \%$ inhibition produced no damping of the oscillation in oxygen uptake. Thus it is possible to consider the respiration of a synchronous culture as having two components. One increases exponentially at all times in the cell cycle, cannot be easily uncoupled and is preferentially blocked by inhibitors of electron transport. The second consists of easily uncoupled electron transport chains which are only inhibited by high concentrations of antimycin $\mathrm{A}$ or $\mathrm{KCN}$. The activity of this component oscillates with a periodicity equal to 0.5 of a cell cycle, presumably because of the periodic synthesis of a rate-limiting entity. The control mechanism involved in the transitions between maximal and minimal respiratory activity is obscure, but may involve interaction with glycolytic reactions in a Pasteur effect. Further work is necessary to identify the metabolic control points involved in the production of the oscillatory respiratory activity.

We acknowledge the interest and encouragment of Professor D. E. Hughes, the skilled technical assistance of Mrs Lynda John, the co-operation of Messrs R. L. Taylor and T. R. Deal (LKB Instruments Ltd) and the loan of the Microcalorimeter. This work was carried out during the tenure of a Science Research Council Research Studentship (R. K.P.).

\section{REFERENCES}

Blumenthal, L. K. \& Zahler, S. A. (1962). Index for measurement of synchronization of cell populations. Science, New York 135, 724 .

Campbell, A. (1957). Synchronization of cell division. Bacteriological Reviews 21, 263-272.

Chance, B. \& Williams, G. R. (1956). The respiratory chain and oxidative phosphorylation. Advances in Enzymology 17, 65-I34.

Cot trell, S. F. \& Avers, C. J. (I970). Evidence of mitochondrial synchrony in synchronous cell cultures of yeast. Biochemical and Biophysical Research Communications 38, 973-980.

ERIKSSON, R. \& WADsö, I. (1971). Design and testing of a flow microcalorimeter for studies of aerobic bacterial growth. Proceedings of the Ist European Biophysics Congress 4, 319-327.

Greksák, M., Haricová, M. \& Weissová, K. (1971). The use of a synchronous yeast culture for the study of mitochondrial biogenesis. Communications of the 7 th Meeting of the European Biochemical Societies, Abstract no. 637 .

Herbert, D., Phipps, P. J. \& Strange, R. E. (1971). Chemical analysis of microbial cells. In Methods in Microbiology, vol. 5B, pp. 209-344. Edited by J. R. Norris and D. W. Ribbons, London and New York: Academic Press.

Heslot, H., Goffeau, A. \& Louis, C. (1970). Respiratory metabolism of a 'petite-negative' yeast, Schizosaccharomyces pombe $972 \mathrm{~h}^{-}$. Journal of Bacteriology 104, 473-481.

Kovač, L., Galeotti, T. \& Hess, B. (I968). Oligomycin-like inhibition of yeast respiration by $N, N$-dicyclohexylcarbodimide, and the nature of energy-coupling in intact yeast cells. Biochimica et biophysica acta I53, 7I5-717.

Lloyd, D. \& Brookman, J. S. G. (1967). An oxygen electrode reaction vessel. Biotechnology and Bioengineering 9, 271-272.

MarCHANT, R. (197x). The initiation of cell-wall synthesis in parasynchronous cultures of Schizosaccharomyces. Archiv fiir Mikrobiologie 78, 205-213.

Mitchison, J. M. (I957). The growth of single cells. I. Schizosaccharomyces pombe. Experimental Cell Research 13, 244-262.

Mitchison, J. M. (I97I). The Biology of the Cell Cycle. Cambridge: Cambridge University Press.

Mitchison, J. M. \& Vincent, W. S. (I965). Preparation of synchronous cell cultures by sedimentation. Nature, London 205, 987-989.

Monk, P. \& Wadsö, I. (I968). A flow micro reaction calorimeter. Acta chemica scandinavica 22 , I $842-1852$.

Nosoh, Y. \& TakamiYa, A. (1962). Synchronization of budding cycle in yeast cells and effect of carbon monoxide and nitrogen-deficiency on the synchrony. Plant and Cell Physiology 3, 53-66. 
OSUmi, M. \& SANDo, N. (1969). Division of yeast mitochondria in synchronous culture. Journal of Electron Microscopy 18, 47-56.

POOLE, R. K. \& LLOYD, D. (1972). Oxygen uptake and activity of respiratory enzymes in synchronouslydividing cultures of Schizosaccharomyces pombe. Communications of the 8th Meeting of the European Biochemical Societies, A.bstract no. 597.

POOLE, R. K. \& LLOYD, D. (1 973). Effect of 2 deoxy-D-glucose on growth and cell walls of Schizosaccharomyces pombe $92 \mathrm{~h}^{-}$. Archiv für Mikrobiologie 88, 257-272.

Scopes, A. W. \& Williamsion, D. H. (1964). The growth and oxygen uptake of synchronously-dividing cultures of Saccharomyces cerevisiae. Experimental Cell Research 35, 361-371.

Umbreit, W. W., Burris, R. H. \& Stauffer, J. F. (1957). In Manometric Techniques, p. I. Minneapolis: Burgess Publishing Co.

WADsö, I. (1968). Design and testing of a micro reaction calorimeter. Acta chemica scandinavica 22, 927-937. Wiemken, A., von Meyenburg, H. K. \& Matile, Ph. (I970). Properties of the vacuole in baker's yeast synchronized with a new method. Acta Facultatis medicae Universitatis brunensis 37, 47-52. 